\title{
Academic Achievement Test in English and Mathematics of Secondary School Students in relation to Gender Differences
}

\author{
Mohd Hasan ${ }^{1}$, Salahuddin Khan ${ }^{2}$
}

\begin{abstract}
:
The present research study aims to examine the academic achievement of secondary school students in relation to gender differences. The study was carried out on a sample of 100 male and female students studying in class IX $^{\text {th }}$ of Aligarh District, U.P. India. Two self developed tools were applied which finally analysed by applying Mean, SD, t-Test and Pearson's Coefficient Correlation (r). Results revealed a significant difference between male and female students in English achievement scores and also no significant difference was found between English and Mathematics achievement scores of IX ${ }^{\text {th }}$ grade male students. Results also revealed low positive correlation between English and Mathematics achievement of male students of IX $^{\text {th }}$ grade and moderate positive correlation between English and Mathematics achievement of female students of $\mathrm{IX}^{\text {th }}$ grade. The results suggested to the need of motivation and encouragement for enhancing academic achievement scores of male and female students.
\end{abstract}

Keywords: Academic Achievement; Gender Differences; English; Mathematics; Secondary

School Students.

English and Mathematics have become a substantial and integral part of organised society. There is a close interaction between English and Mathematics and the economic, social, political and educational issue of the society, Therefore, there is hardly any need to justify the place of English and mathematics in a scheme of general education for school children. There is an indispensable relationship between these two subjects and also determines the extent and length of educational development of any community, society and country as a whole. There is much discussion about the relationship between gender and achievement in English and Mathematics education in these days. The concern has arisen because less number of females enters the academic and professional areas related to English and Mathematics. Here it would appropriate to understand the word "Gender". It is the word that is inclusive of both boys and girls on the basis of social justice and mutual respect.

${ }^{1}$ Department of Education, Aligarh Muslim University, Aligarh, U.P. India

${ }^{2}$ Department of Education, Aligarh Muslim University, Aligarh, U.P. India

(C) 2015 I M Hasan, S Khan; licensee IJIP. This is an Open Access Research distributed under the terms of the Creative Commons Attribution License (http://creativecommons.org/licenses/by/2.0), which permits unrestricted use, distribution, and reproduction in any Medium, provided the original work is properly cited. 


\section{Academic Achievement Test in English and Mathematics of Secondary School Students in relation to Gender Differences}

Meanwhile, investigation of gender equity has attracted the attention of many scholars in national and international study. According to Stevenson (1992) cross cultural research is necessary to assess the generality of gender differences in academic performance and for gaining insight into variables that might be related to such differences.

By comparison, gender differences in achievement, especially English have not been consistent and continue to be a much debated topic. Much of the work investigating those goals has been conducted in the domain of Mathematics. Results from studies that have considered the academic goals in English appear to be consistent with findings in Mathematics. Neog,S (1990) reported that the over achievers in English were found to be more prove to be women wanted, less intelligent, emotionally less stable, less enthusiastic, less adventurous, socially group depended and less controlled than the over achievers in Mathematics. Rangappa (1993) found that a successful language learner at upper primary level has a high Mathematical ability and achieve a high score in other subject as well. In Mathematics studies have shown that boys hold more stereotyped views than girls do. Friedman (1989) noted that until age of 10 either no differences between genders or differences favouring are observed and also observed that in five of seven studies of XII grade boys out performed XII grade girls.

It is hard to find a more controversial topic in recent researches than of sex differences in the performance of English and Mathematics. Keeping in view for going discussion, it was thought appropriate to study the academic achievement of boys and girls of $\mathrm{IX}^{\text {th }}$ grade students in subjects English and Mathematics achievement. These differences have not been studied adequately in Indian condition. This being the reason the researchers undertook the present study which attempt to investigate gender differences in English and Mathematics.

\section{REVIEW OF THE LITERATURE}

Heller \& Parsons (1981) studied the sex differences in teacher's evaluative feedback and student's expectancies for Mathematics. Results revealed no sex differences in the pattern of evaluative feedback used by teacher. No difference was also resulted in student's expectancies for success on familiar tasks. However, girls are found with lower expectancies than boys on unfamiliar or future tasks. Meese \& Parsons (1982) carried out their research on sex difference in Mathematics achievement: towards a model of academic choice and concluded that competence in Mathematics has long been identified as a critical skill directly related to educational and occupational choice. As compared to men, fewer women elect to take advance level of Mathematics course to enter mathematically oriented career. Dass, P.A (1984) examined the English reading comprehension of English medium students of IX ${ }^{\text {th }}$ grade. Study revealed that the mean scores of girls were higher than boys. Sex difference was also found on reading comprehension in English. Friedman (1989) performed a Meta analysis on Mathematics and the Gender gap. Study revealed small average sex difference as well as sex differences in performance also showed declined trend over the advancement of years. Hyde et al. (1990) 
carried out a Meta analysis on Mathematics performance with reference to gender differences, and concluded that no gender difference was found in problem solving at elementary or middle school level. A small Gender differences in Mathematics performance were found. Neog (1990) studied about personality characteristics of students in relation to over achievement of in English and Mathematics. Results revealed that women stood on as over achievers in English with the personality characteristics of less intelligent, emotional less stable, less enthusiastic, less adventurous, socially group dependent than the over achievers in Mathematics. Under achievers in English were found more prove to tender mindedness, apprehensive and controlled than the under achievers in English.

Besides above discussed studies, such study like, Bag, Anjali (1990) reported boys showed more proficiency in English usage than girls, Jha (1992) found positive significant correlation between proper attitude of middle school students towards English and Mathematics, Ewers et.al (1993) concluded that male showed more self- efficacy strength for Mathematics task than shown by female counterparts, Skaavik and Ran Kin (1994) reported no significant difference between the sexes in Mathematics achievement, Royer et.al (1999) found no gender difference on simple mathematical retrieval task, Rehman (2003) concluded that a significant difference male and female students in Mathematics achievement, Anjum (2007) found significant difference between academic achievements of high school over and under achiever girls in Mathematics were also tried to study the gender differences in the achievement of Mathematics and English with different dimensions. However, a complete research gap has been marked in relation to the study of gender differences in English and Mathematic achievement of IX ${ }^{\text {the }}$ grade students.

\section{DEFINITIONS OF KEY TERMS English}

The term English means when it is used as noun (with a plural verb) when it is used as adjective it can be understood as characteristics or culture of England or of its people. When we go into the origin of English we can derive it from England, one would think. But in fact the language name is found long before the country name. However, here English is considered as a school subject.

\section{Mathematics}

According to various definitions, Mathematics is the science of numbers and their operations, interrelations, combinations, generalizations and abstractions and of space configurations and their structure, measurement, transformation and generalization. According to science dictionary, "Mathematics is the science of measurement, relationship, and properties of quantities and sets using numbers and symbols."

\section{Gender Differences}

A gender difference is a distinction of biological and/or physiological characteristics typically associated with either male or female or species in general. While the social sciences sometimes approaches gender as a social construct and gender studies particularly do, research in the 
natural sciences investigates whether biological differences in males and females influences the development of gender in humans. Gender is the characteristics, whether biological or socially influenced, by which people define male and female.

\section{ACADEMIC ACHIEVEMENT}

Academic achievement is the performance in academic subjects or the performance in a particular course by academic achievement; we mean the performance of a learner after course of instructions and measure in terms of masks and grades obtained in a given area of knowledge or skills acquired after undergoing a program of instruction. According to C.V. Good (1973). "Academic achievement is the knowledge attained or skill developed in the school subjects usually designed by test scores are makes assigned by Teacher, or both".

\section{VARIABLES IN THE PRESENT STUDY}

Dependent Variable: Academic Achievement of English and Mathematics Independent Variable: Gender (Male \& Female)

\section{OBJECTIVES OF THE STUDY}

The purpose of this research project is to find out the Achievement of IXth grade students in English and Mathematics and to investigate whether there is any difference between male and female students in achievement in English and Mathematics of IX ${ }^{\text {th }}$ grade students. The objectives of the study are:

1. To see the difference in English achievement between male and female of IX ${ }^{\text {th }}$ grade students.

2. To see the difference in Mathematics achievement between male and female of IXth grade students.

3. To see the difference in English and Mathematics achievement of male of IX ${ }^{\text {th }}$ grade students.

4. To see the difference in English and Mathematics achievement of female of IX ${ }^{\text {th }}$ grade students.

5. To see the relation in English and Mathematics of male of $\mathrm{IX}^{\text {th }}$ grade students.

6. To see the relation in English and Mathematics of female of IX ${ }^{\text {th }}$ grade students.

\section{HYPOTHESES OF STUDY}

In the present study the hypotheses have been formulated in a null form. The confidence level for the purpose of excepting or rejecting the hypothesis in the study $0.05,0.01$ and 0.10 levels keeping in view the objective of the study, the following research hypothesis has been formulated and to be tested against the empirical data.

1. There is no significant difference in English achievement of male and female IXth grade students.

2. There is no significant difference in Mathematics achievement of male and female of IX ${ }^{\text {th }}$ grade students.

3. There is no significant difference in English and Mathematics achievement of male of IX ${ }^{\text {th }}$ grade students. 
4. There is no significant difference in English and Mathematics achievement of female of $\mathrm{IX}^{\text {th }}$ grade students.

5. There is no relation in English and Mathematics of male of IX ${ }^{\text {th }}$ grade students.

6. There is no relation in English and Mathematics of female of IX ${ }^{\text {th }}$ grade students.

\section{LIMITATIONS OF THE STUDY}

The limitations of study are as follows:

1. The study is conducted only on 100 students of two A.M.U's Secondary Schools. One cannot generalise this research to the whole country because of the difference in condition and circumstances.

2. Though various statistical techniques could have been used for analysis of the data but due to lack of time, t-test and product moment correlation coefficient(r) are used.

3. The results that may have been reported reflect merely what students' achievement in English and Mathematics in schools of (A.M.U.) and the findings may be quite different at another time or in other cultural setting.

4. The data obtained and findings reported concerning achievement of students do not indicate what 'ought to be' nor do they simply' what has been found' is best and true once and for all.

5. The generalization of the findings of this study is limited to secondary schools of A.M.U. Aligarh, U.P. India.

\section{METHOD}

The present study is descriptive in nature. The researcher has adopted survey method to carry out the study. The school survey is the comprehensive study of existing conditions of the school.

\section{Population and Sample}

The sample of the study consists of 100 students and was selected from two schools of AMU, districts Aligarh, U.P. India. Out of 100 students of IX ${ }^{\text {th }}$ grade, there were 50 boys and 50 girls.

\section{Tools Used in the Study}

In order to meet the objectives of the study, following tools were used:

1. English Achievement Test for IX ${ }^{\text {th }}$ grade students.

2. Mathematics Achievement Test for IX ${ }^{\text {th }}$ grade students.

Above mentioned both tests are constructed by the researcher to test the achievement in English and Mathematics. Each test is consisted of 20 objectives type questions of the concerned disciplines. Summation of marks or scores achieved by the students in all the questions was considered as his or her achievement scores in both subjects. The scoring was done on the basis of responses of the students on the every items of the each scale and score 1 was awarded on each correct answer and 0 for wrong option, the securing maximum score 20 and minimum of 0 on each scale. 


\section{Statistical Techniques Used}

The analysis of data is done by using the following statistical techniques: Means, Standard deviation (SD), Standard error of the mean (SEM), Standard error of the difference between two means (SED), $t$-Test (to see the significance of the difference between two means), Correlation (r) $\{$ to see the relationship in the academic achievement score of English and Mathematics .

\section{ANALYSIS AND INTERPRETATION OF THE DATA}

Table 1: Gender Wise Significant Differences in Student's Achievement in English of IX ${ }^{\text {th }}$ Grade

\begin{tabular}{|l|c|c|c|c|c|c|}
\hline Gender & $\mathbf{N}$ & $\begin{array}{c}\text { Mean } \\
\text { achievement } \\
\text { score }\end{array}$ & $\begin{array}{c}\text { \% of mean } \\
\text { achievement } \\
\text { score }\end{array}$ & $\begin{array}{c}\text { Standard } \\
\text { deviation(SD) }\end{array}$ & $\begin{array}{c}\text { t- } \\
\text { value }\end{array}$ & $\begin{array}{c}\text { Level of } \\
\text { significance }\end{array}$ \\
\hline Male & 50 & 15.92 & $79.6 \%$ & 3.08 & \multirow{2}{*}{0} & \multirow{2}{*}{0.05} \\
\hline Female & 50 & 13.62 & $68.1 \%$ & 3.20 & 2.45 & \\
\hline
\end{tabular}

The total number of male and female students of $\mathrm{IX}^{\text {th }}$ grade was 50 each as indicated by table 1 The mean Mathematics achievement score of male student is 16.36 and SD=0.99. In case of female students the mean Mathematics achievement scores is 15.0 and standard deviation SD is zero. The statistically calculated value of $t$ is 3.68 which is significant at 0.01 level with 98df. The result clearly indicates that there is difference between mean scores of Mathematics of male and female students of $\mathrm{IX}^{\text {th }}$ grades. The male student had shown significantly higher performance in Mathematics than their female counterpart. Therefore, the second hypothesis that "there is no significant difference between male and female student in Mathematics achievement of IX ${ }^{\text {th }}$ grade students" is rejected at 0.01 levels. The graphical representation of mean achievement score in Mathematics of male and female students of IX ${ }^{\text {th }}$ grade.

Table 2: Significant Differences in Student's Achievement in English and Mathematics of Male Students of $I^{\text {th }}$ Grade

\begin{tabular}{|c|c|c|c|c|c|c|}
\hline Gender & $\mathbf{N}$ & $\begin{array}{c}\text { Mean } \\
\text { achievement } \\
\text { score }\end{array}$ & $\begin{array}{c}\text { \% of mean } \\
\text { achievement } \\
\text { score }\end{array}$ & $\begin{array}{c}\text { Standard } \\
\text { deviation } \\
\text { (SD) }\end{array}$ & $\begin{array}{c}\text { t- } \\
\text { value }\end{array}$ & $\begin{array}{c}\text { Level of } \\
\text { significance }\end{array}$ \\
\hline Mathematics & 50 & 16.36 & $81.80 \%$ & 0.99 & 0.58 & $\begin{array}{c}\text { Not } \\
\text { significant }\end{array}$ \\
\hline
\end{tabular}

It is evident from the table 2 that the number of male students of $\mathrm{IX}^{\text {th }}$ grade in subject English and Mathematics was 50 each. The mean Mathematics achievement score of male student is 16.36 and $\mathrm{SD}=0.99$. In case of English subject the mean achievement scores is 15.92 and standard deviation $\mathrm{SD}=3.08$. The statistically calculated value of $\mathrm{t}$ is 0.58 which is not significant with 98df. The result clearly indicates that there is no significant difference between Mathematics achievement score and English achievement score of IX ${ }^{\text {th }}$ grades male students. 
The male student of IX ${ }^{\text {th }}$ class had shown equal performance in Mathematics and English. So the third hypothesis stating that "there is no significant difference between Mathematics achievement and English achievement scores of IX ${ }^{\text {th }}$ grades male students" is accepted with $98 \mathrm{df}$.

Table 3: Significant Differences in Student's Achievement in English and Mathematics of Female Students of $\mathrm{IX}^{\text {th }}$ Grade

\begin{tabular}{|l|c|c|c|c|c|c|}
\hline \multicolumn{1}{|c|}{ Gender } & $\mathbf{N}$ & $\begin{array}{c}\text { Mean } \\
\text { achievement } \\
\text { score }\end{array}$ & $\begin{array}{c}\text { \% of mean } \\
\text { achievement } \\
\text { score }\end{array}$ & $\begin{array}{c}\text { Standard } \\
\text { deviation(S } \\
\mathbf{D})\end{array}$ & $\begin{array}{c}\mathbf{t}- \\
\text { value }\end{array}$ & $\begin{array}{c}\text { Level of } \\
\text { significance }\end{array}$ \\
\hline Mathematics & 50 & 15.00 & $75.00 \%$ & 0.00 & \multirow{2}{*}{3.06} & 0.01 \\
\hline English & 50 & 13.62 & $68.1 \%$ & 3.20 & & \\
\hline
\end{tabular}

It is evident from the table 3 that the number of female students of IX $^{\text {th }}$ grade in subject English and Mathematics was 50 each. The mean Mathematics achievement score of female student of $\mathrm{IX}^{\text {th }}$ standard is 15 and $\mathrm{SD}=0.0$. In case of English subject the mean achievement scores is 13.62 and standard deviation $\mathrm{SD}=3.20$. The statistically calculated value of $\mathrm{t}$ is 3.06 which are significant at level 0.01 with $98 \mathrm{df}$. The result clearly indicates that there is significant difference between Mathematics achievement score and English achievement score of $\mathrm{IX}^{\text {th }}$ grades female students. The female student of $\mathrm{IX}^{\text {th }}$ class had shown significantly higher performance in Mathematics than English. So the fourth hypothesis stating that "there is no significant difference between Mathematics achievement and English achievement scores of IX ${ }^{\text {th }}$ grades female students" is rejected at 0.01 levels as $98 \mathrm{df}$.

Table 4: Correlation in Subjects English and Mathematics of Male Students of IXth Grade

\begin{tabular}{|l|l|c|l|c|l|l|l|l|l|l|}
\hline $\mathbf{N}$ & $\sum \mathbf{X}$ & $\bar{X}$ & $\sum \mathbf{Y}$ & $\bar{Y}$ & $\sum \mathbf{X Y}$ & $\sum \mathbf{X}^{2}$ & $\sum \mathbf{Y}^{2}$ & $\boldsymbol{\delta x}$ & $\delta \mathbf{y}$ & $\mathbf{r}$ \\
\hline $\mathbf{5 0}$ & $\mathbf{7 9 6}$ & $\mathbf{1 5 . 9 2}$ & $\mathbf{8 1 8}$ & $\mathbf{1 6 . 3 6}$ & $\mathbf{1 3 0 5 8}$ & $\mathbf{1 3 2 2 2}$ & $\mathbf{1 3 9 0 5}$ & $\mathbf{3 . 0 8}$ & $\mathbf{0 . 9 9}$ & $\mathbf{0 . 2 1}$ \\
\hline
\end{tabular}

It is depicted from table 4 that the number of male students of IX $^{\text {th }}$ grade in subject English and Mathematics was 50 each. The mean Mathematics achievement score of IX grade male student is 16.36 and $\mathrm{SD}=0.99$. In case of English subject the mean achievement scores is 15.92 and standard deviation $\mathrm{SD}=3.08$. The statistically calculated value of coefficient of correlation $(r)=0.211$. It is being revealed that there is a low positive correlation between Mathematics and English achievement of IX ${ }^{\text {th }}$ grades male students. So the fifth hypothesis stating that "there is no correlation between Mathematics achievement and English achievement scores of IX ${ }^{\text {th }}$ grades male students" is rejected. 
Table 5: Correlation in Subjects English and Mathematics of Female Students of $\mathrm{IX}^{\text {th }}$ Grade

\begin{tabular}{|l|l|c|l|c|l|l|l|l|l|l|}
\hline $\mathbf{N}$ & $\sum \mathbf{X}$ & $\bar{X}$ & $\sum \mathbf{Y}$ & $\bar{Y}$ & $\sum \mathbf{X Y}$ & $\sum \mathbf{X}^{2}$ & $\sum \mathbf{Y}^{2}$ & $\boldsymbol{\delta} \mathbf{x}$ & $\boldsymbol{\delta y}$ & $\mathbf{r}$ \\
\hline $\mathbf{5 0}$ & $\mathbf{6 8 1}$ & $\mathbf{1 3 . 6 2}$ & $\mathbf{7 5 0}$ & $\mathbf{1 5 . 0 0}$ & $\mathbf{1 0 4 1 2}$ & $\mathbf{9 7 7 7}$ & $\mathbf{1 1 4 4 1 0 5}$ & $\mathbf{3 . 2 0}$ & $\mathbf{0 . 0 0}$ & $\mathbf{0 . 4 5}$ \\
\hline
\end{tabular}

It is depicted from table 5 that the number of female students of $\mathrm{IX}^{\text {th }}$ grade in subject English and Mathematics was 50 each. The mean Mathematics achievement score of IX ${ }^{\text {th }}$ grade female student is 15.0 and $\mathrm{SD}=0.0$. In case of English subject the mean achievement scores is 13.62 and standard deviation $\mathrm{SD}=3.20$. The statistically calculated value of coefficient of correlation $(r)=0.45$. it is being revealed that there is a moderate positive correlation between Mathematics and English achievement of IX ${ }^{\text {th }}$ grades female students. So the fifth hypothesis stating that "there is no correlation between Mathematics achievement and English achievement scores of IX ${ }^{\text {th }}$ grades female students" is rejected at 0.01 level of significance.

\section{MAJOR FINDINGS}

On the basis of t-test and product moment correlation coefficient ( $\mathrm{r}$ ) applied to investigate gender basis difference in mean English and Mathematics scores of $\mathrm{IX}^{\text {th }}$ grade students, the following major findings are derived as.

1. There exists a significant difference between male and female students in English achievement scores. The male students have more academic achievement in English than their female counterpart.

2. There exists a significant difference between male and female students in Mathematics achievement scores. The male students have more academic achievement in English than their female counterpart.

3. There does not exist significant difference between English and Mathematics achievement scores of $\mathrm{IX}^{\text {th }}$ grade male students. The male student of $\mathrm{IX}^{\text {th }}$ class had shown equal performance in English and Mathematics.

4. There exists a significant difference in English and Mathematics achievement scores of $\mathrm{IX}^{\text {th }}$ grade female students. The female student of $\mathrm{IX}^{\text {th }}$ class had shown more academic achievement in Mathematics than English.

5. There exist low positive correlation between English and Mathematics achievement of male students of IX ${ }^{\text {th }}$ grade.

6. There exist moderate positive correlation between English and Mathematics achievement of female students of IX ${ }^{\text {th }}$ grade.

\section{DISCUSSION}

The finding of present study clearly shows that performance of the students both in English and Mathematics is found to be good. The mean achievement in combined English and Mathematics of male student was 16.14 and for girls 14.31 out of maximum score of 20.In term of percentage the mean achievement scores for boys was 80\% and for girls was $71.11 \%$. Thus the performance of students in English and Mathematics is found to be good. This result is different with the finding of Prakash 
and Pandey (1996), who also reported that the performance of students in both Mathematics and language in primary schools was low. It was also found that at secondary level in subjects English and Mathematics, male students have significantly higher mean achievement scores in English as well as Mathematics than their female counterparts. Kulkarni (1970), reported boys had higher achievement level than the girls in Mathematics at primary, middle and secondary stage, in as many as 15 states. Friedman (1989) concluded the study that the gender gap favouring boys were common in high school. Dossey, et.al. (1988) conducted a study with 17 years old student and found out performance girls. Campbell (1991) conducted a study and found female scored low.

\section{EDUCATIONAL IMPLICATIONS}

The present study has come with that male students are performing better in mathematics and English than their female counterparts. The study also revealed that lack of motivation and low expectation of female students may be the cause of being trailed to male students. Thus, there is need to focus on the overall teaching learning environment of schools. Teachers, who are accorded as the leader of the class room teaching, should take this responsibility and should also encourage and motivate both boys and girls to excel in the academic arena. So the findings of the study would definitely help in to chalk out the plan, related to the improvement of academic achievement of male and female.

\section{SUGGESTIONS FURTHER RESEARCH}

Some of these research problems related to this area are given below and may be taken by researchers in future.

1. Student's socio-economic status and their achievement in English and Mathematics.

2. Student's personal factor and achievement in English and Mathematics.

3. Effects of parent's education and occupation on their achievement in English and Mathematics.

4. Gifted and non-gifted children and their achievement in English and Mathematics.

5. Creative and non-creative children and their achievement in English and Mathematics.

6. Influence of class size on their achievement in English and Mathematics.

7. Gender gap linked to differential socialization for high achieving English and Mathematics students.

8. Influence of classroom climate on achievement in English and Mathematics.

9. Socio economic and gender effects on in English and Mathematics achievement.

10. School effectiveness on in English and Mathematics achievement.

\section{CONCLUSION}

The good performance of the students in general at secondary level is indicative of either good environment of English and Mathematics or the students belong to medium social strata of the population, in terms of economic condition and education. 
Further, it had been found that boys have significantly higher academic achievement in subject English and Mathematics than the girls. Why these gender gaps do occurs in English and Mathematics education? Different groups of researchers have supplied very divergent answer to this question. There are many factors like cognitive, motivational, biological and parent's attitude which are responsible for creating gender gap. Two factors, one cognitive and other, motivational may account for tendency for males to make more egoistical attribution than females.

\section{ACKNOWLEDGEMENT}

The authors acknowledge Prof Mohammad Parvez, Dr. Mahmood Ali and Razia B, Department of Education, Aligarh Muslim University (A.M.U), Aligarh for their sagacious guidance and remarkable suggestions during the course of the work.

\section{REFERENCE}

1. Ahuja, G. C and, Pramila. (1988). Reading Comprehension Tests (with close and multiple choice items for classes VIII ${ }^{\text {th }}$, IXth and $X^{\text {th }}$ ) independent study. Mysore, Central Institute of Indian Language. In Buch M.B $1988 \mathrm{~V}^{\text {th }}$ Survey Vol ${ }^{\text {nd }}$ (1988-92), NCERT, P-738.

2. New Delhi. Anjum, S. (2007). Study of anxiety in relation to over and under achievement of girls Mathematics at high school level. M.Ed dissertation (unpublished), A.M.U. Aligarh.

3. Azzolino, A. (1998). The language of Math classroom. http:www.mathnstuff. Com/papers/lags/pages.

4. Bag, Anjali. (1990). A cross sectional study on the differential aptitudes of the students in English. Ph.d., Edu,Univ. of Kalyani in Buch, M.B. Survey of Educational Research, $\mathrm{V}^{\text {th }}$ survey vol $2^{\text {nd }}(1988-1992)$ NCERT,New Delhi,page-743.

5. Birenbaum, Menucha, and Kraemer, Roberta. (1995). Gender and ethnic-group difference in causal attributions for success and failure in Mathematics and language examinations. Journal of Cross-cultural Psychology, Vol. 26, pp.342-356.

6. Campbell, J.R., and Beandry, S.J. (1998).Gender gap linked to differential socialization for high-achieving senior Mathematics student. Journal of Educational Research, vol. 91, no. 3, pp.140-147.

7. Casey, M Bith, Nuttal, Ronald 1., and Pezaris, Elizabeth. (1977). Mediators of gender differences in Mathematics college entrance test scores: a comparison of spatial skills with internalized beliefs and anxieties. Developmental Psychology,Vol. 33, pp.669-680.

8. Dass, P.A. (1984). A study of reading comprehension in English of students of English medium secondary school of standard $X^{\text {th }}$ of central Gujarat in context of some socio psycho factor. Buch, M.B (1991) IV th Survey of Educational Research Vol. (0I), (198386), NCERT, New Delhi, page-629. 
9. Ewers, Cynthia, A. and Wood, Nancy, 1. (1993). Sex and ability differences in children's Mathematics self-efficiency and prediction accuracy. Learning and Individual, Vol. 5, pp.259-267.

10. Fennema, E., and Sherman, J. (1978). Sex-related differences in Mathematics achievement and related factors: a further study. Journal for Research in Mathematics Education, Vol. 9, pp.189-203.

11. Friedman, 1. (1989). Mathematics and the gender gap: a meta-analysis of recent study on sex difference in Mathematics tasks. Review of Educational Research, Vol.59, no.2, pp. 185-213.

12. Friend, H. (1985). The effect of science and Mathematics integration on selected seventh grade student's attitudes towards \& achievement in science. School Science and Mathematics, Vol.85 (6), pp.453-461.

13. Good, C.V. (1973). Dictionary of Education, McGraw=Hill Book Company, New York.

14. Greene, B.A., Debacker, T.K., Ravindran, B., and Krows, A.J. (1999). Goals, values, and beliefs as predictors of achievement and effort in high school. Mathematics classes Sex Roles, Vol. 40 (5), pp. 421-458.

15. Gupta, K.M (1996).Teachers' performance in Mathematics and Reading Test. Indian Educational Review Vol. 3 (1), 92-104.

16. Hawes, Lynnesalp, Hawes, Gene, R. (1982). The concise dictionary of education, Van Nostrandreinhold Company, New York, Clincinnale, Toronto, London, Melbourne.

17. Heller, K.A, and Parsons, J.E. (1981). Sex difference in teacher's evaluative feedback and student's expectancies for success in Mathematics. Child Development, Vol.52, pp.10151019.

18. Helwig, R., Anderson, 1., and Tindal, G. (2001). Influence of elementary student gender on teacher's perceptions of Mathematics achievement. Journal of Educational Research, Vol.95, No. 2, pp.93-102.

19. Hilton, T.L. and Berglund, G.W. (1974). Sex differences in Mathematics achievement: a longitudinal study. Journal of Educational Research, Vol. 67, pp. 231-237.

20. Hy, J.S, Fennema, E., and Lamon, S.J. (1990). Gender differences in Mathematics performance: a meta-analysis. Psychological Bulletin, Vol.107, No.2, pp.139-155.

21. Jha, J.S. (1992). Attitude towards Mathematics and achievement: a correlative study. Educational Review, Vol. xcviii, No. \& 6.

22. Kevelu, J.M., and Rogers, W.T. (19998). A multi level analysis of cultural experience and gender influences on causal attributions to perceived performance in Mathematics. British journal of Educational Psychology, Vol.68, pp.25-37.

23. Ma, Xen. (1997). Reciprocal relationship between attitude towards Mathematics and achievements in Mathematics. Journal of Educational Research, Vol.90, No.4, pp.221229.

24. Meece, J.L., and Holt, K. (1993). A pattern analysis of student's achievement goals. Journal of Educational Psychology, vol.85, pp.582-590. 
25. Meece, J.L., and Parsons, J.E. (1982). Sex differences in Mathematics achievement: toward a model of academic choice. Psychological Bulletin, Vol.91, No.2, pp.324-348.

26. Mitxel, H. E. (1982. Encyclopaedia of educational research fifth edition, the free press, $A$ division of MacMillan publishing Co, New York.

27. Neog, S (1990). A study of personality characteristics of under achievers across any two school discipline. Doctoral Theses, Education, A.M.U. Aligarh.

28. Rahman, A. (2003). Influence of Attitude, Gender, Parental Education, Types of Shool and Coaching and Guidance on Academic achievement in Mathematics of $\mathrm{V}^{\text {th }}$ grade students. M.Ed dissertation (unpublished), A.M.U. Aligarh.

29. Rangappa, K. T (1993). Effect of reading ability on mathematical performance. Psycolingua Vol.23 (1), PP. 25-30.

30. Royer, James M, Tronsky, Loel N, Chan, Yan, Jackson, Stanliy J, and Marchant Horace. (1999). Math fact retrieval as the cognitive mechanism under lying gender differences in math-test performance. Contemporary Educational Psychology, Vol.24, pp. 181-266.

31. Sharma, R. K (1986). A study of problem of teaching English in Bihar" in Buch, M.B, IVth Survey of Educational Research. Vol. $1^{\text {st }}$ (1983-86) NCERT, New Delhi, p-661.

32. Skaalvik, E. M., and Rankin, R.J. (1994). Gender differences in Mathematics and verbal achievement self perception and motivation. British Journal of Psychology, Vol.64, pp.419-428.

33. Taylor, P.T., Leder, G.C., Pollard, G.H., and Atkin, W.J. (1996). Gender difference in Mathematics: trend in performance. Psychological Report, Vol.78, pp.3-17. 